\title{
Comparative Morphological and Anatomical Research of Leaves 6 Sorts of Laurels Noble (Laurus Nobilis L.), Growing in the Conditions of an Introduction in the Nikitsky Botanical Garden
}

\author{
Serebryanaya Fatima Kazbekovna ${ }^{1,2}$, Orlov Aleksei Nikolaevich¹, Konovalov Dmitryi Alexeevich ', Naida Mahmu- \\ dovna Nasuhova ${ }^{1}$
}

\begin{abstract}
Serebryanaya Fatima Kazbekovna ${ }^{1,2}$, Orlov Aleksei Nikolaevich ${ }^{1}$, Konovalov Dmitryi Alexeevich ${ }^{1}$, Naida Mahmudovna Nasuhova ${ }^{1}$
\end{abstract}

'Department of Pharmacognosy and Botany, Pyatigorsk Medical and Pharmaceutical Institute, a branch of Volgograd State Medical University Ministry of Health of the Russian Federation, Pyatigorsk, 357532, Kalinina av.11, RUSSIA.

${ }^{2}$ Ecological and botanical station Pyatigorsk of Botanical institute of Russian Academy of sciences, 197376, Saint-Petersburg, Prof. Popova av. 2, RUSSIA.

\section{Correspondence}

Fatima Kazbekovna Serebryanaya

Department of Pharmacognosy and Botany, Pyatigorsk Medical and Pharmaceutical Institute, a branch of Volgograd State Medical University Ministry of Health of the Russian Federation, Pyatigorsk, 357532, Kalinina av.11, RUSSIA.

Phone No: 89283776847

E-mail: fatimasereb@yandex.ru

\section{History}

- Submission Date: 18-10-2017;

- Review completed: 03-11-2017;

- Accepted Date: 19-11-2017

DOI : 10.5530/pj.2018.1.29

\section{Article Available online}

http://www.phcogj.com/v10/i1

\section{Copyright}

(C) 2018 Phcog.Net. This is an open access article distributed under the terms of the Creative Commons Attribution 4.0 International license.

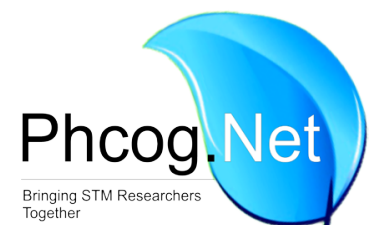

\section{ABSTRACT}

This research is a fragment of complex studying of grades of laurels of the noble, growing in the territory of botanical gardens of Pyatigorsk medical and pharmaceutical institute and the Nikitsky botanical garden which is carried out based on department of botany and a pharmacognosy of the Pyatigorsk medical and pharmaceutical institute. Introduction: Research objective is to conduct a comparative morphological and anatomical research of leaves of 6 sorts of Laurus nobilis. Material and Methods: The exemplars of leaves of 6 grades of laurels noble, growing in the territory of the Nikitsky botanical garden (the settlement of Nikita, Crimea republic). When carrying out comparative morphometric, micromorphological, histochemical methods. Results: The comparative morphometric research of a leaf plate is conducted, at the same time the form of a leaf plate, character of a top, basis and margined of a leaf plate were estimated. In the analysis of features of a micromorphological structure carried out the analysis of an anatomic structure of scapes of leaves and a structure of a transversal cut of a sheet plate, a top and bottom epidermal of a sheet plate. The form of the cross- section of the petiole is horseshoe-shaped, dredging is absent or falciform with the expressed dredging, rounded triangular form, dredging is absent. The presence or absence of coverage trichomes, the presence only at the top party of a scape and it is presented by individual monocelled lengthiest hairs, is presented by a small amount of individual, monocelled small hairs on the top party of a petiole it is presented by individual monocelled small hairs. Existence and arrangement of a resin ducts are presented in big quantity, especially there is a lot of around a phloem part of a vascular bundle or the ducts are presented in a great many, there is a lot of them, both around a phloem part of a vascular bundle, and under epidermis. Existence and arrangement of a sclerenchyme -around the vascular bundle from two parties or it is presented by groups of fibers around the vascular bundle or absent. Conclusion: As for an anatomic structure of an epidermis of a leaf plate, differences in a histological structure of an epidermis of the studied grades of laurels noble it is not revealed. The following signs are characteristic of all studied exemplars: leaf plate of hypostomatic type. Stomates are present only at the lower part of an epidermis. The stomatal type is anomocytic. Epidermal cages of the lower epidermis have the extended form with sinuous anticlinal walls. Anticlinal walls of the main cages of the top epidermis have the reference uniform thickenings In the analysis of features of a micromorphological structure carried out the analysis of an anatomic structure of scapes of leaves and a structure of a transversal cut of a sheet plate, a top and bottom epidermal of a sheet plate.

Key words: Laurus nobilis, Comparative micromorphological study, Cross-section of leaf and petiole, Anatomical topographical schemes.

\section{INTRODUCTION}

This research is a fragment of complex studying of grades of laurels of the noble, growing in the territory of botanical gardens of Pyatigorsk medical and pharmaceutical institute and the Nikitsky botanical garden which is carried out based on department of botany and a pharmacognosy of the Pyatigorsk medical and pharmaceutical institute. Exemplars of fragments of escapes and leaves are kindly provided by employees of the Nikitsky botanical garden (the settlement of Nikita, Crimea republic). As the main active ingredi-

ents in leaves of laurels noble are described: components of an essential oil, sesquiterpenic lactones, fatty acids and phenolic connections (flavonoids and phenolic acids). ${ }^{2}$

Chemical composition includes biologically the active materials, including more than 30 sesquiterpenic lactones, the most important of which are kostunolide and dehydrokostucolactone which have various pharmacological properties, are revealed. An interest in these connections is bound to their

Cite this article: Serebryanaya FK, Orlov A, Konovalov DA, Nasukhova NM. Comparative Morphological and Anatomical Research of Leaves 6 Sorts of Laurels Noble (Laurus Nobilis L.), Growing in the Conditions of an Introduction in the Nikitsky Botanical Garden. Pharmacog J. 2018;10(1):172-8. 
expressed immunomodulatory and potent cytotoxic action concerning some lines of tumor cells. ${ }^{5}$

Besides, these connections showed high activity at treatment of viral and microbial infections, and have antiseptic, anti-inflammatory, wound healing, glistogonny properties. ${ }^{3}$

\section{MATERIAL AND METHODS}

The exemplars of leaves of 6 grades of laurels noble (Laurus nobilis L.), growing in the territory of the Nikitsky botanical garden (the settlement of Nikita, Crimea republic). When carrying out comparative morphometric, micromorphological, histochemical methods.

\section{RESULTS AND DISCUSSION}

The morphological characteristic, laurels noble - evergreen, low (15-20 $\mathrm{m})$, a tree or a treelike bush with brown, sometimes dark gray, smooth bark. ${ }^{1,3}$ Leaves are prime, oblong, a little wavy on edge, from above shining, from below opaque and lighter; the type of venation is pinnate. ${ }^{1}$ Flowers diclinous, on 4-8 in umbrella in the bract inflorescences concluded before blossoming in spherical wrappers from four parts; the perianth consists of a short tube and 4-6 equal falling-down shares. Stamens in the stamen male flowers in number 8-12 and more, located in 2-3 circles, with two pieces of iron on threads, boots with two nests opening longwise. Female flowers with one pestle and 4, are more-rare $2-3$, underdeveloped stamens; the ovary is top, 1-nesting with 1 bud, it is poorly shipped in a receptacle. A fruit - black-blue stone fruit.1

The area of distribution of this species covers the Mediterranean region, the laurels grow on limestones in the lower forest mountain belt. The introduction of this look is widespread in France, Italy, Spain and Greece and on the Black Sea coast of the Caucasus and the Crimea. ${ }^{1}$

Research objective isto conduct a comparative morphological and anatomical research of leaves of 6 sorts of laurels noble (Laurus nobilis L.)

Besides, the comparative morphometric research of a leaf plate is conducted, at the same time the form of a leaf plate, character of a top, basis and margined of a leaf plate were estimated. Results are presented in Table 1 and Figure 1.

Common are revealed morphological structures of laurel (Laurus nobilis L.), such as leaves prime, smooth-edged, leathery, from above dark green, from below light green, it is wide-lanceolate on short, grooved, naked scapes; the leaf bases - rounded. The sheet edge widely - wavy. The type of the venation is pinnate. We prepared the the comparative morphometric characteristics of the form of the leaves of 6 sorts of Laurus nobilis L. (Table 1).

In the analysis of features of a micromorphological structure carried out the analysis of an anatomic structure of scapes of leaves and a structure of a transversal cut of a sheet plate, a top and bottom epidermal of a sheet plate. Results are presented in Tables 2-3 and in Figures 2,3,4,5.

When carrying out the analysis of distinctions of an anatomic structure of a scape of a leaf of 6 sorts of laurels noble the following distinctive micromorphological features, such as form on a transverse section of the petiole, existence or lack of the reference dredging on the adaxial part, existence and the nature of the omission formed by simple monocelled hairs are revealed. As for an anatomic structure of an epidermis of a leaf plate, differences in a histological structure of an epidermis of the studied grades of laurels noble it is not revealed. The following signs are characteristic of all studied exemplars: leaf plate of hypostomatic type. Stomates are present only at the lower part of an epidermis. The stomatal type is anomocytic. Epidermal cages of the lower epidermis have the extended form with sinuous anticlinal walls. Anticlinal walls of the main cages of the top epidermis have the reference uniform thickenings (Figure 6).

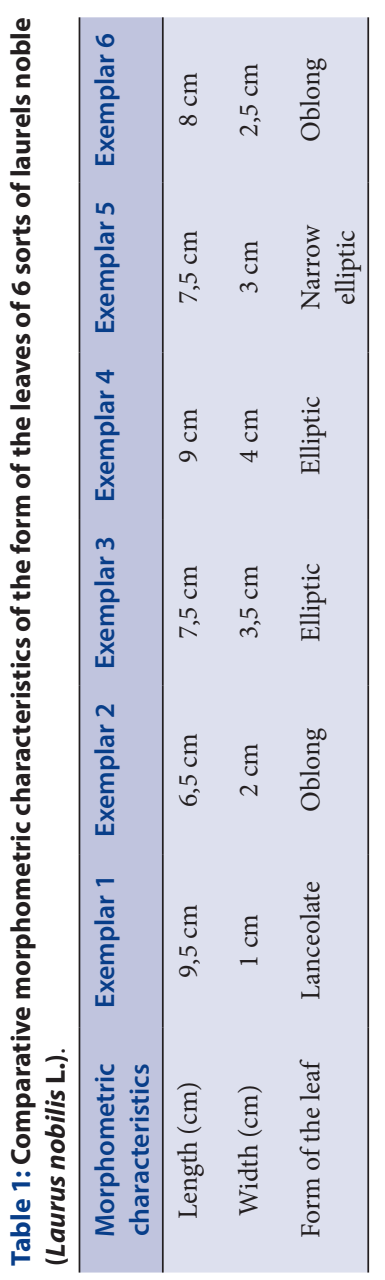



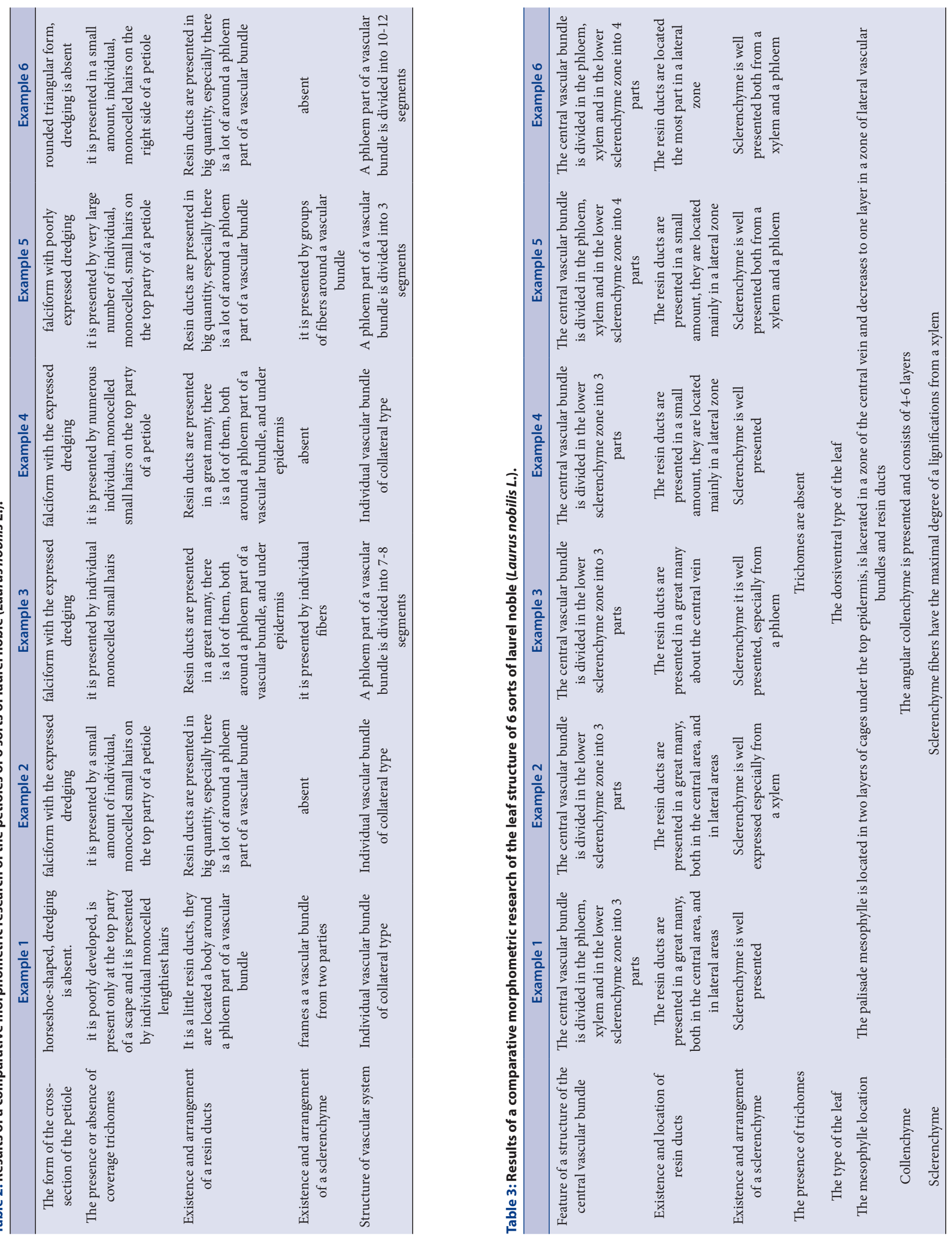


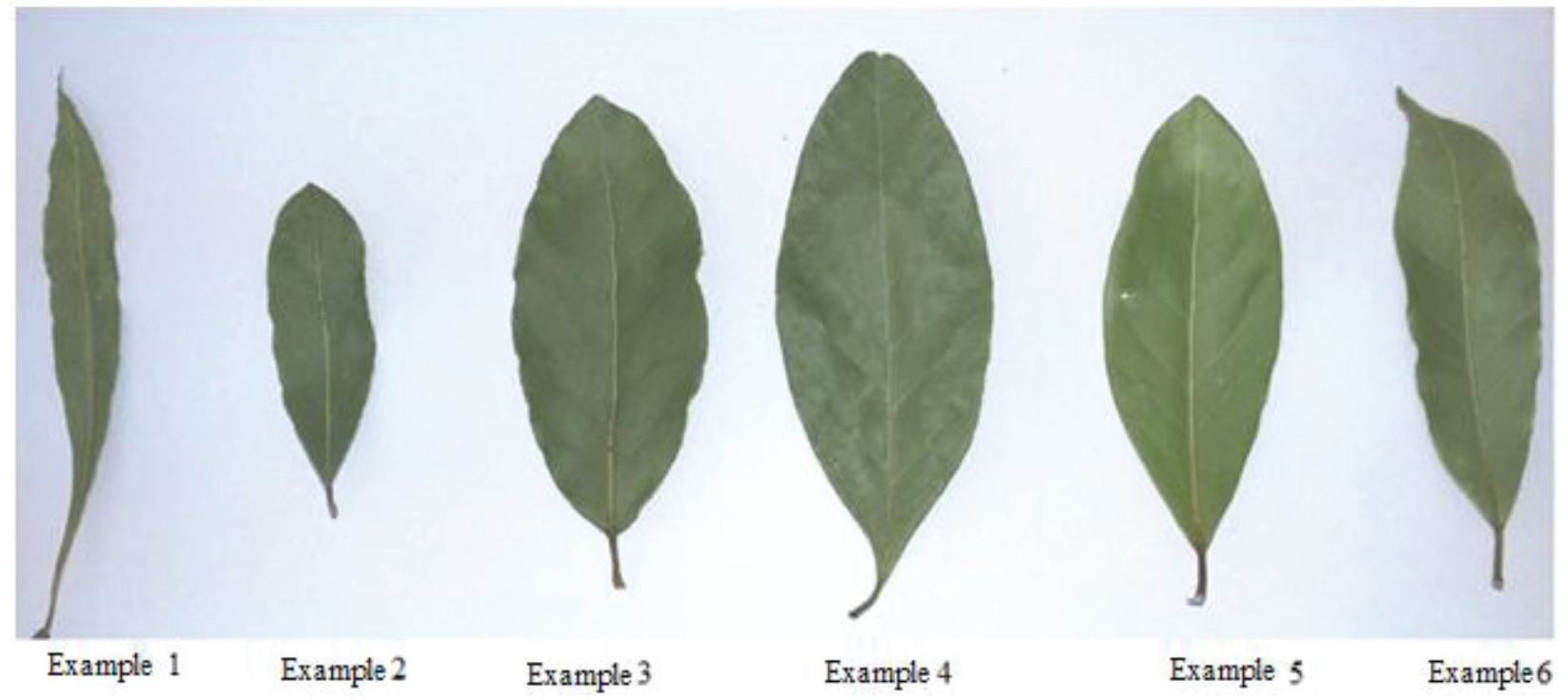

Figure 1: Comparative morphological research of the form of the leaves of 6 sorts of laurels noble (Laurus nobilis L.).
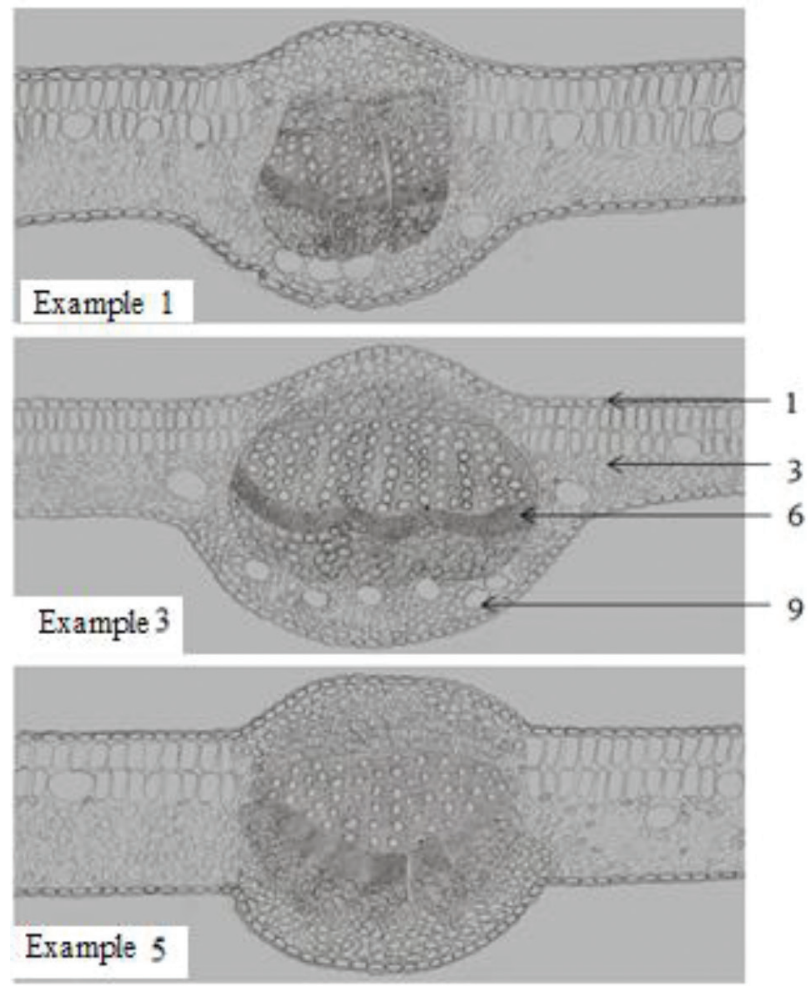
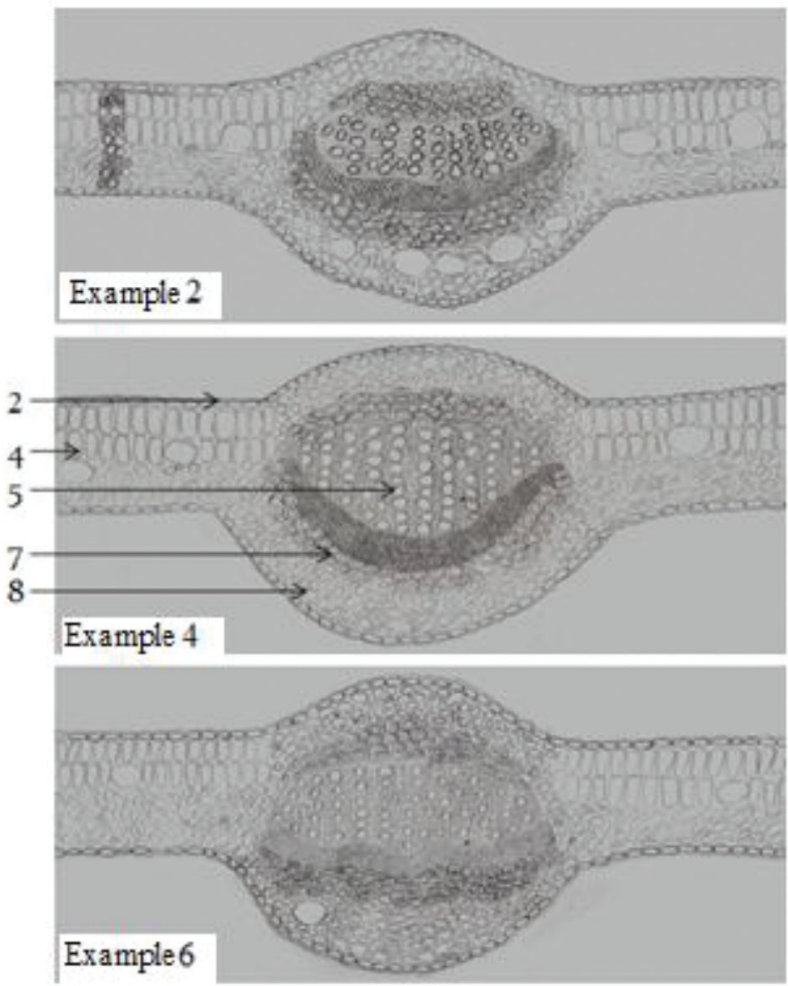

Figure 2: Anatomical topographical schemes of an anatomic structure of a cross section of the of a leaf plate of six sorts of laurels noble (Laurus nobilis L.) 1. Epidermis. 2. Cuticle. 3. Spongy mesophylle. 4. The palisade mesophylle. 5. Xylem. 6. Phloem. 7. Sclerenchyme. 8. Collenchyme. 9. Resin ducts.

The comparative morphometric research of a leaf plate is conducted, at the same time the form of a leaf plate, character of a top, basis and margined of a leaf plate were estimated. In the analysis of features of a micromorphological structure carried out the analysis of an anatomic structure of scapes of leaves and a structure of a transversal cut of a sheet plate, a top and bottom epidermal of a sheet plate. The dorsiventral type of the leaf. The palisade mesophylleis located in two layers of cages under the top epidermis, is lacerated in a zone of the central vein and decreases to one layer in a zone of lateral vascular bundles and resin ducts. The angular collenchyme is presented and consists of 4-6 layers. Sclerenchyme fibers have the maximal degree of a lignifications from a xylem.

The form of the cross- section of the petiole is horseshoe-shaped, dredging is absent or falciform with the expressed dredging, rounded triangular form, dredging is absent. The presence or absence of coverage trichomes, the presence only at the top party of a scape and it is 


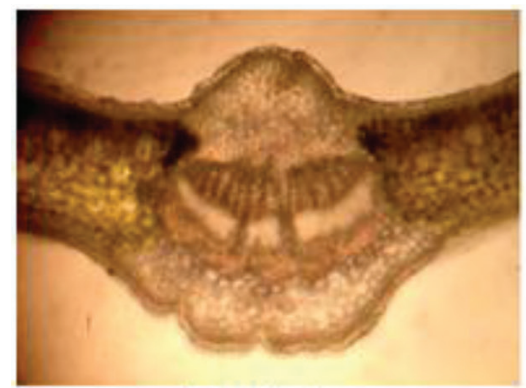

Example 1

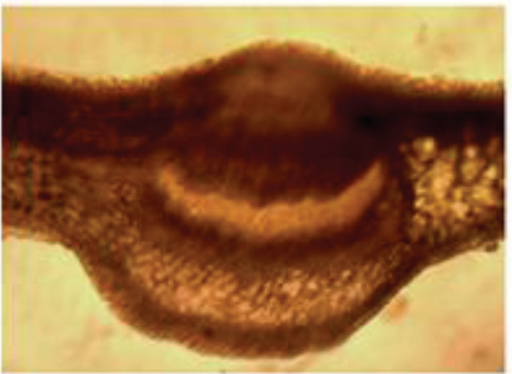

Example 4

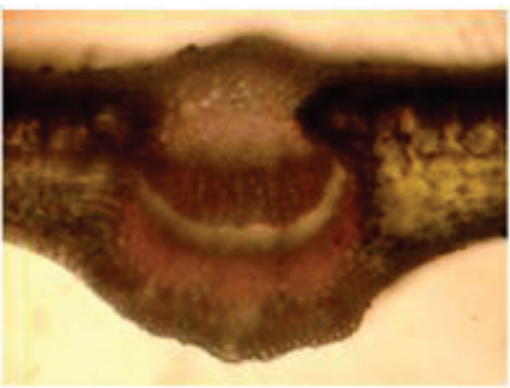

Example 2

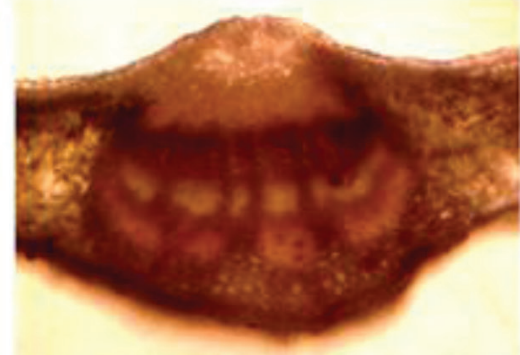

Example 5

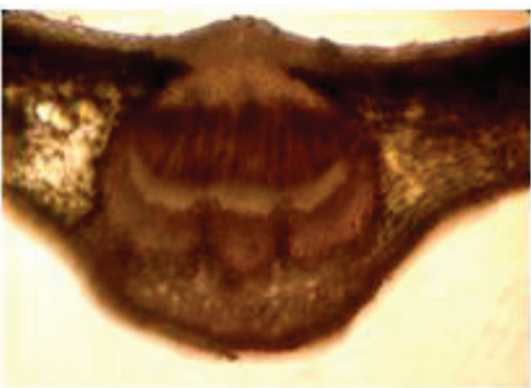

Example 3

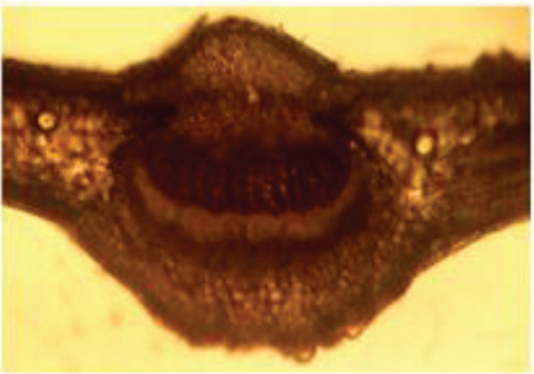

Example6

Figure 3: Microphotographs of an anatomic structure of a cross section of the leaf plate of six sorts of laurels noble (Laurus nobilis L.).

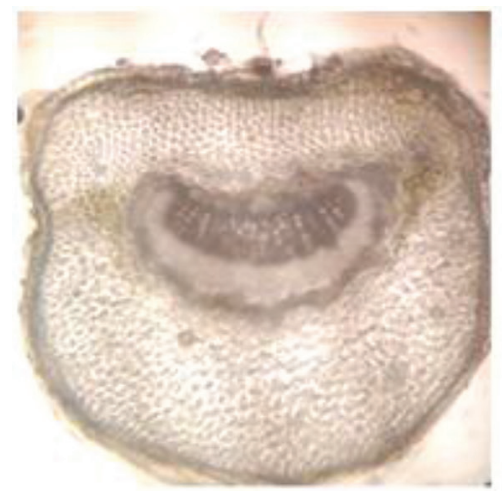

Example 1

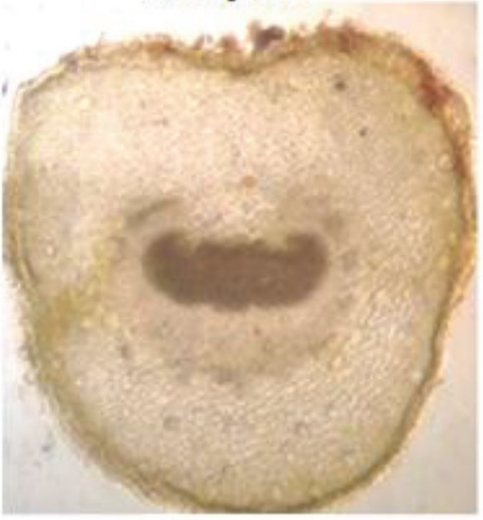

Example 4

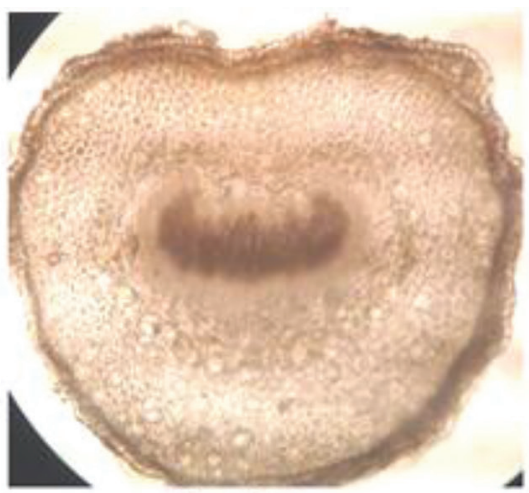

Example 2

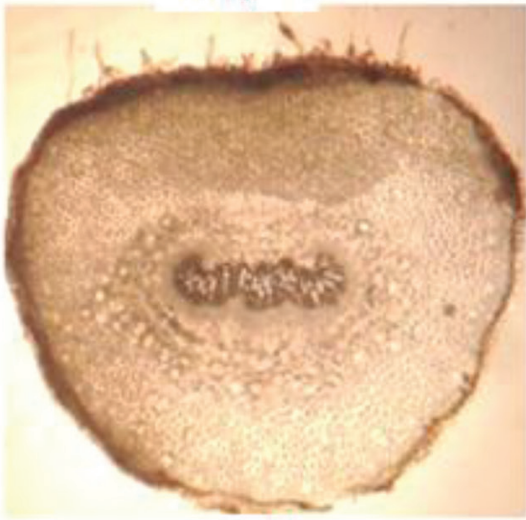

Example 5

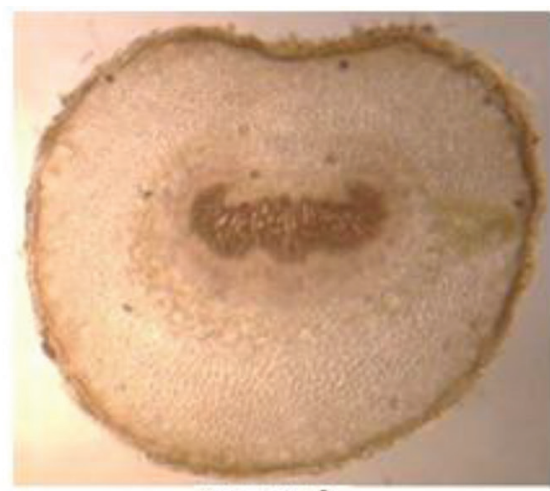

Example 3

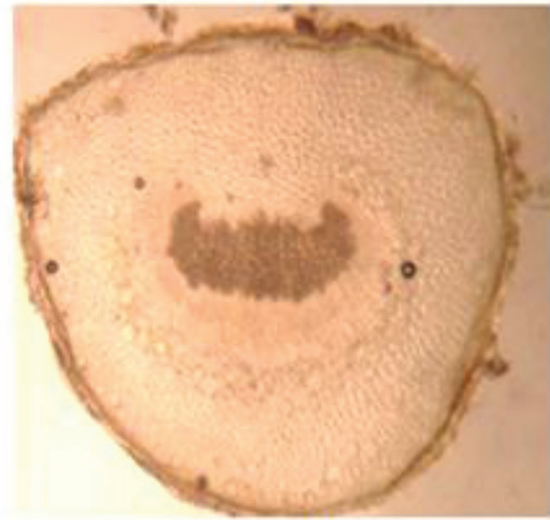

Example6

Figure 4: Microphotographs of an anatomic structure of a cross section of the petiole of six sorts of laurels noble (Laurus nobilis L.). 

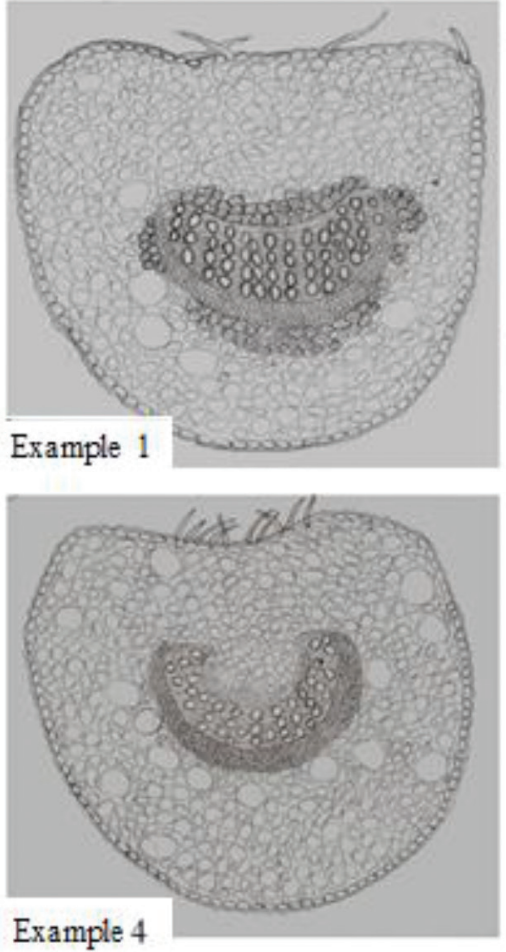
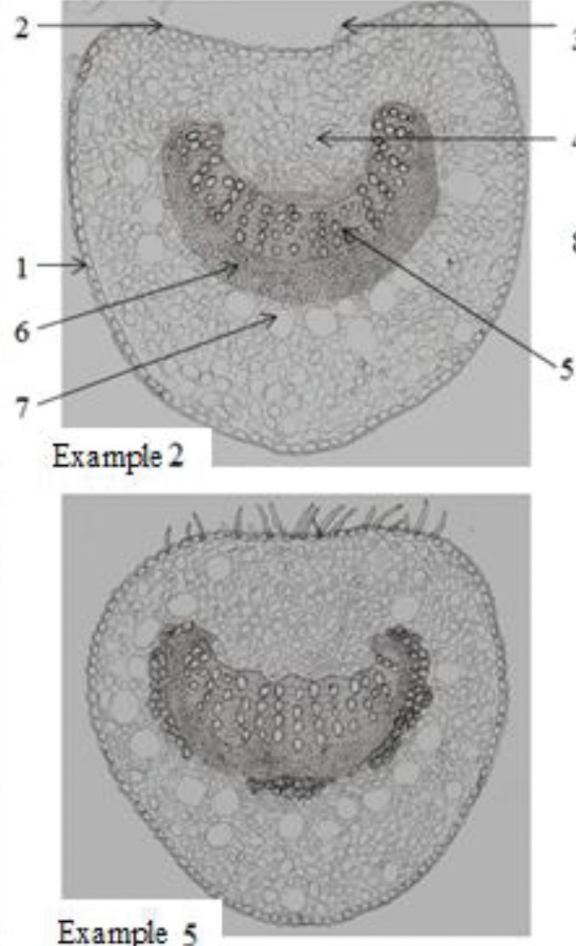
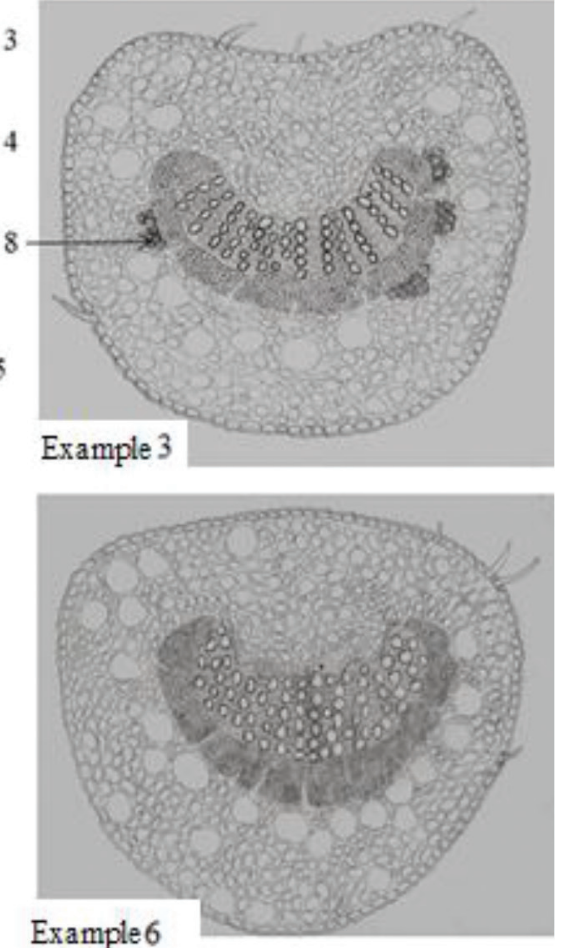

Figure 5: Anatomical topographical schemes of an anatomic structure of a cross section of the of a petiole of six sorts of laurels noble (Laurus nobilis L.).

1. Cuticle. 2. Epidermis. 3. Individual monocelled hair. 4. Collenchyme. 5. Xylem. 6. Phloem. 7. Resin ducts. 8. Sclerenchyme.
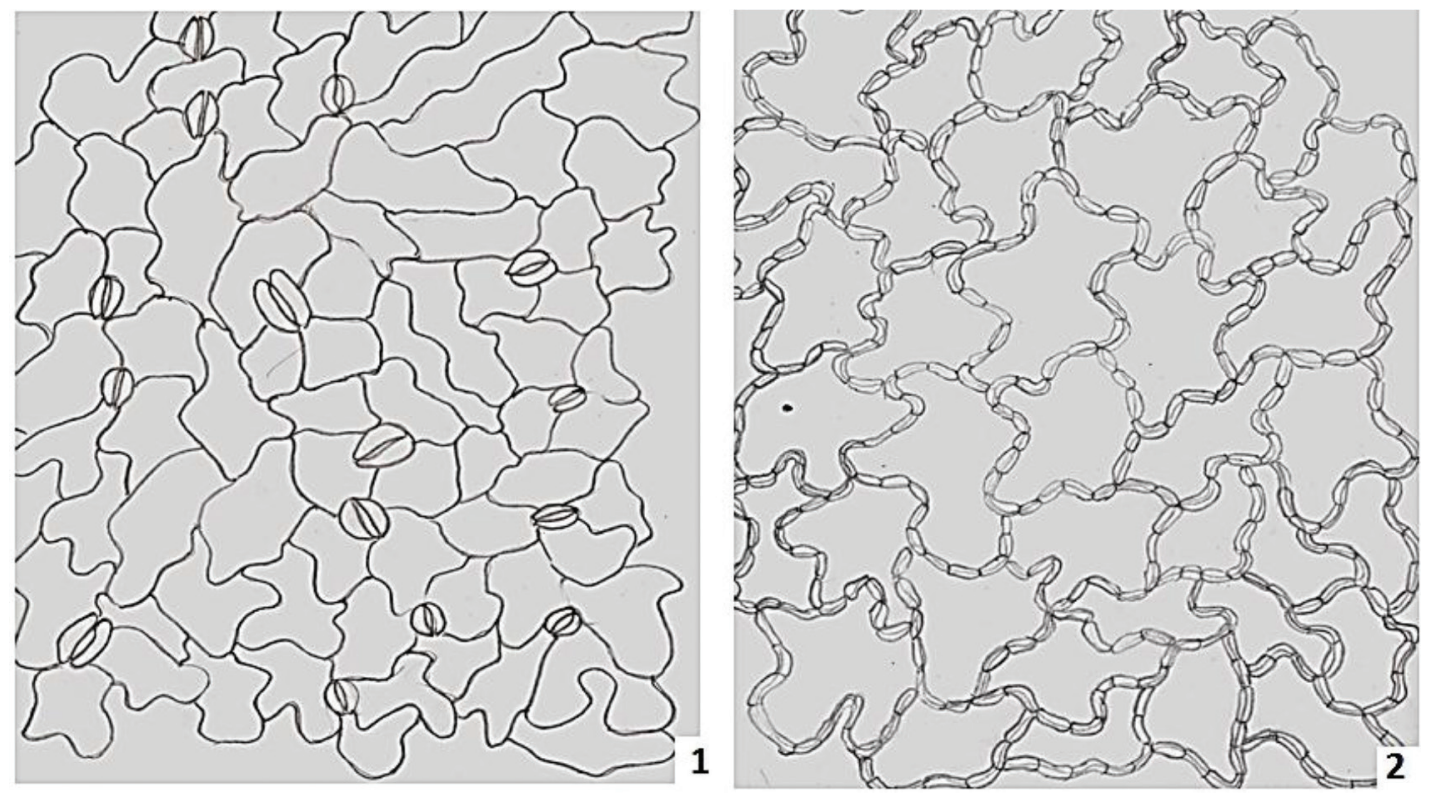

Figure 6: Anatomic structure of an epidermis of a leaf plate of sorts of laurels noble (Laurus nobilis L.).

presented by individual monocelled lengthiest hairs, is presented by a small amount of individual, monocelled small hairs on the top party of a petiole it is presented by individual monocelled small hairs.

The existence and arrangement of the resin ducts are presented in big quantity, especially there is a lot of around a phloem part of a vascular bundle or the ducts are presented in a great many, there is a lot of them, both around a phloem part of a vascular bundle, and under epidermis.
Existence and arrangement of a sclerenchyme -around the vascular bundle from two parties or it is presented by groups of fibers around the vascular bundle or absent.

\section{CONCLUSION}

As for an anatomic structure of an epidermis of a leaf plate, differences in a histological structure of an epidermis of the studied grades of lau- 
rels noble it is not revealed. The following signs are characteristic of all studied exemplars: leaf plate of hypostomatic type. Stomates are present only at the lower part of an epidermis. The stomatal type is anomocytic. Epidermal cages of the lower epidermis have the extended form with sinuous anticlinal walls. Anticlinal walls of the main cages of the top epidermis have the reference uniform thickenings In the analysis of features of a micromorphological structure carried out the analysis of an anatomic structure of scapes of leaves and a structure of a transversal cut of a sheet plate, a top and bottom epidermal of a sheet plate. The conducted researches can be used further by drawing up complex normative documentation on medicinal vegetable raw materials.

\section{ACKNOWLEDGMENT}

This research project was carried out with the assistance of the Fund for the development of research. The authors are grateful to the head of Pyatigorsk medical and pharmaceutical Institute V. L. Adgienko.

\section{CONFLICT OF INTEREST}

When performing this research conflicts of interest did not arise, since all of the authors have conducted research work comprehensively.

\section{REFERENCES}

1. Nikitina AA, Pankova IA. Anatomic atlas of the useful and some poisonous plants. //- M.: Science. 1982:387-93.

2. Nasukhova NM, Konovalov DA. Chromatographic studying of phenolic connections of leaves of laurels noble//Pharmacological and botanical studying of simples. 2015;70:66-8.

3. Senchenko SP, Agova LA, Bobrovsky IN, Nasukhova NM, Konovalov DA. Development and validation of a technique of the quantitative definition of sesquiterpenic lactones in leaves of Laurus nobilis $L$. with use of high performance solution chromatography//The Medical bulletin of the North Caucasus. 2016;4:529-32.

4. Harchenko AL. Morphological and anatomical features of the leaves of Laurus nobilis $L$. in the conditions of the southern coast of the Crimea//-the Bulletin of the Nikitsky botanical garden. 2008;97:28-31. 5

5. Julianti E. Sesquiterpenes from the leaves of Laurus nobilis L. / E. Julianti KH, Jang S, Lee [et al]// Phytochemistry.2012;80:70-6.doi: 10.1016/j.phytochem.2012.05.013.

6. Serebrynaya FK, Nasuhova NM, Konovalov DA. Morphological and Anatomical 6. Study of the leaves of Laurus nobilis L. (Lauraceae), growing in the Introduction of the Northern Caucasus region (Russia). Pharmacogn J. 2017;9(4): 519-22.

\section{ABOUT AUTHORS}

Serebryanaya Fatima Kazbekovna: Candidate of Pharmaceutical Sciences, associate Professor, Department of Pharmacognosy and Botany Pyatigorsk medical-pharmaceutical Institute - branch GBOU VPO Volggmu Ministry of health of Russia, RUSSIA. Ecological and botanical station Pyatigorsk of Botanical institute of Russian Academy of sciences, 197376, Saint-Petersburg, Prof. Popova av. 2, RUSSIA. Research interests: study of the flora of the Caucasian Mineral Waters, micromorphologic study of plants of the Alpine and subnival zones of the zones of the Central Caucasus.

Orlov Aleksei Nikolaevich: Student of Pyatigorsk medical-pharmaceutical Institute - branch GBOU VPO Volggmu Ministry of health of Russia, RUSSIA. Research interests: botany, plant anatomy, phytochemistry, pharmacognosy.

Konovalov Dmitryi Alexeevich: Doctor of Pharmaceutical Sciences, Professor, Department of Pharmacognosy and Botany Pyatigorsk medical-pharmaceutical Institute - branch GBOU VPO Volggmu Ministry of health of Russia, RUSSIA. Research interests: Phytochemistry, Pharmacognosy, Sesquiterpenic lactones, Polyacetylene compounds.

Nasuhova Naida Mahmudovna: Postgraduate student at the Chair of Pharmacognosy, Department of Pharmacognosy and Botany Pyatigorsk medical-pharmaceutical Institute - branch GBOU VPO Volggmu Ministry of health of Russia, RUSSIA. Research interests: phytochemistry, pharmacognosy

Cite this article: Serebryanaya FK, Orlov A, Konovalov DA, Nasukhova NM. Comparative Morphological and Anatomical Research of Leaves 6 Sorts of Laurels Noble (Laurus Nobilis L.), Growing in the Conditions of an Introduction in the Nikitsky Botanical Garden. Pharmacog J. 2018;10(1):172-8. 